\title{
Influence of thermal ageing on the stability of polymer bulk heterojunction solar cells
}

Sabine Bertho ${ }^{a}$, Ilse Haeldermans ${ }^{\mathrm{a}}$, Ann Swinnen ${ }^{\mathrm{a}}$, Wouter Moons ${ }^{\mathrm{a}}$, Tom Martens ${ }^{\mathrm{a}}$, Laurence Lutsen $^{\mathrm{b}}$, Dirk Vanderzande ${ }^{\mathrm{a}, \mathrm{b}}$, Jean Manca $^{\mathrm{a}, \mathrm{b}}$, Alessia Senes $^{\mathrm{c}}$, Annalisa Bonfiglio ${ }^{\mathrm{c}}$

${ }^{a}$ Institute for Materials Reseach (IMO), Hasselt University, Wetenschapspark 1, B-3590

Diepenbeek (Belgium), ${ }^{b}$ IMEC vzw, Division IMOMEC, Wetenschapspark 1, B-3590 Diepenbeek, Belgium, ${ }^{c}$ University of Cagliari, Italy

e-mail: sabine.bertho@uhasselt.be

\begin{abstract}
A new approach is presented in order to improve the thermal stability of polymer:PCBM bulk heterojunction solar cells. The central idea in this approach is the use of a polymer with high glass transition temperature $\left(\mathrm{T}_{\mathrm{g}}\right)$, well above the normal operating temperatures of the devices. In this paper a PPV-derivative with a $\mathrm{T}_{\mathrm{g}}$ of $150^{\circ} \mathrm{C}$ was used as electron donor and the thermal stability of the obtained solar cells was compared with solar cells based on the reference material Poly[2methoxy-5-(3',7'-dimethyloctyloxy)-1,4-phenylene vinylene] (MDMO-PPV) with a $\mathrm{T}_{\mathrm{g}}$ of $45^{\circ} \mathrm{C}$. The use of the material with higher glass transition temperature resulted in a significant improvement of the thermal stability of the photovoltaic parameters. Furthermore, a systematic TEM study demonstrates that the better thermal stability of performance coincides with a more stable active layer morphology. Both improvements are attributed to the reduced free movement of the electron donor material ([6-6]-phenyl $\mathrm{C}_{61}$ butyric acid methyl ester, PCBM) within the active layer of the solar cell.
\end{abstract}


Keywords: Organic photovoltaics, thermal stability, glass transition temperature

\section{Introduction}

Over the last decade great improvements have been made in the field of organic solar cells. An important breakthrough came with the introduction of a blend of an electron-donor-type polymer and suitable electron-acceptor material as active layer. ${ }^{[1,2]}$ Compared to former bilayer structures, the contact area between the donor and acceptor material was enlarged, resulting in more efficient exciton dissociation and AM 1.5 power conversion efficiencies in the range of $1 \%$. Improvement of film morphology by altering the casting conditions of MDMO-PPV:PCBM based photoactive layers resulted in 2.5 to $2.9 \%$ efficient organic solar cells. ${ }^{[3,4]}$ Nowadays efficiencies of $5 \%$ are achieved through the use of high mobility donor polymers (e.g. P3HT) and through a continued nanoscale control of the morphology of the donor-acceptor interpenetrating networks. ${ }^{[5]}$ One of the general bottlenecks of organic solar cells is their poor stability. A low resistance towards oxygen, light, high temperatures etc. results in a degradation of the solar cells. ${ }^{[6-10]}$ It has been reported by Neugebauer et al. that the use of fullerenes in a blend with a polymer gave an improved stability compared with single component devices due to a slower degradation of the polymer in the mixture. ${ }^{[11,12]}$ However, recent studies show that the fullerenes induce a thermal instability of the active layer morphology, yielding observations such as phase separation and PCBM clustering. ${ }^{[13,14]}$ Annealing treatments bring along the demixing of polymer and PCBM, resulting in a reduced interfacial area and less efficient exciton dissociation. Due to this link between the active layer morphology and the performance of solar cells, several solutions have been proposed to improve the thermal stability of organic solar cells by nanomorphology control. A possible approach is the use of diblock-copolymers, consisting of donor- and acceptor-blocks, which could render stable phase separated structures on the scale of the respective block lengths. ${ }^{[15,16]}$ In P3HT based solar 
cells, the thermal stability could be improved by using a low fullerene content in the active layer. ${ }^{[5]}$ This prevented clustering of PCBM under an annealing treatment without hampering the crystallization of P3HT. In this study, a novel approach is presented, based on the use of a high $\mathrm{T}_{\mathrm{g}}$ polymer as electron donor. For this purpose, we use a PPV with a high glass transition temperature $\left(\mathrm{T}_{\mathrm{g}} \approx 150^{\circ} \mathrm{C}\right.$ ). This 'High $\mathrm{T}_{\mathrm{g}} \mathrm{PPV}$ ' (Figure 1 ) is a copolymer designed by Merck. The synthetic route is described by Becker et al. ${ }^{[17]}$ The thermal stability of the photovoltaic output parameters and of the bulk morphology for the obtained solar cells is compared with reference MDMOPPV:PCBM solar cells.

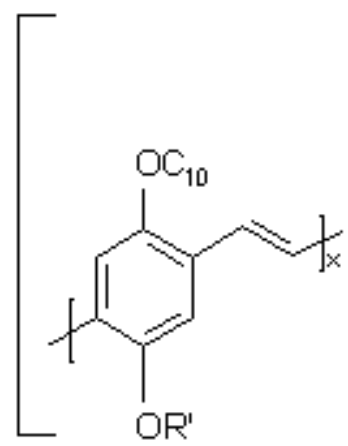

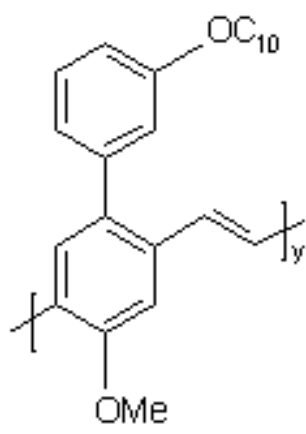<smiles>[R]Oc1ccc(-c2cc(C(C)(C)C)ccc2/C=C/C)cc1</smiles>

Figure 1. 'High $T_{g}$ PPV': a copolymer designed by Merck with a glass transition temperature of about $150^{\circ} \mathrm{C} .^{[17]}$

\section{Experimental}

Bulk heterojunction solar cells were made according to standard preparation guidelines. Indium tin oxide (ITO, 100nm) coated glass plates were cleaned 10' in an ultrasonic bath with successively: soap, demineralised water, acetone and boiling isopropanol. A 60nm thick Poly(3,4ethylenedioxythiophene-polystyrenesulfonate (PEDOT-PSS (Bayer)) layer was spincoated on the ITO structure. The substrates were dried for $20^{\prime}$ on a hotplate at $120^{\circ} \mathrm{C}$. The active layer, with thickness of $120 \mathrm{~nm}$, consisting of a blend of donor polymer (MDMO-PPV (Merck) or 'High $\mathrm{T}_{g}$ PPV' (Merck)) and acceptor material ([6-6]-phenyl $\mathrm{C}_{61}$ butyric acid methyl ester, PCBM (Nano-C)) 
was spincoated on top of the PEDOT-PSS layer. The blends were spincoated from a solution in chlorobenzene with a polymer:PCBM ratio of 1:4. The concentrations of the solutions were respectively $0.5 \mathrm{wt} \%$ and $0.3 \mathrm{wt} \%$ (weight percentage of polymer in chlorobenzene solvent) for MDMO-PPV and 'High $\mathrm{T}_{\mathrm{g}}$ PPV'. To obtain good dissolving the MDMO-PPV:PCBM solution was stirred over night at $50^{\circ} \mathrm{C}$; the 'High $\mathrm{T}_{\mathrm{g}} \mathrm{PPV}$ ':PCBM solution was stirred for a week at $50^{\circ} \mathrm{C}$. Finally, the Al top electrode of $80 \mathrm{~nm}$ was evaporated on top of the active layer. The IVcharacteristics were measured with an Oriel solar simulator equipped with a Xenon Short Arc lamp with a power of $150 \mathrm{~W}$. The annealing treatment was carried out on a hotplate in a glovebox with nitrogen atmosphere and in the dark to avoid degradation due to oxygen and UV radiation.

After the IV-measurements, the active layer of the solar cells was studied with a Transmission Electron Microscope (Philips CM12-STEM).

\section{Results and discussion}

Figure 2 shows the decay of the short circuit current, the fill factor and the efficiency of solar cells with an active layer of either 'High $\mathrm{T}_{\mathrm{g}}$ PPV':PCBM (1:4) or MDMO-PPV:PCBM (1:4). For each point in the graphs, corresponding to a different annealing time, a new sample containing four solar cells has been used. 

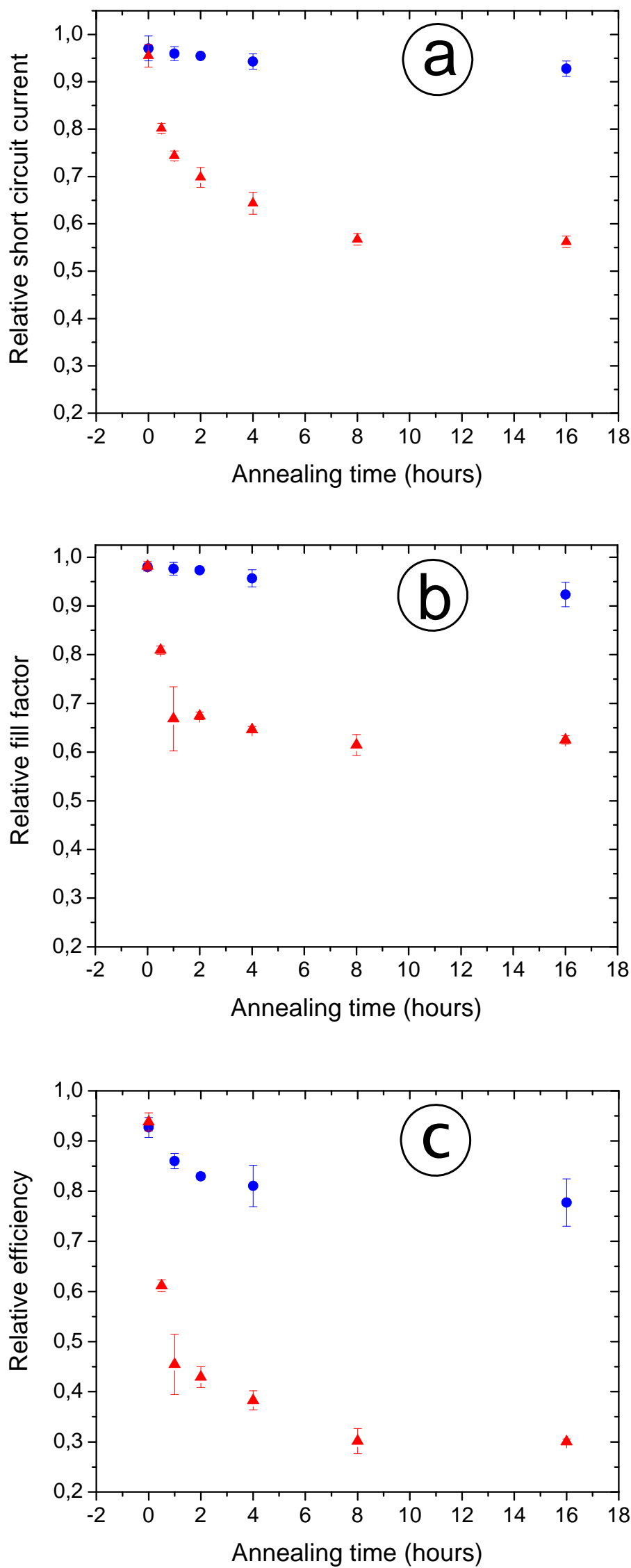
Figure 2. Decay of the relative short circuit current (a), the fill factor (b) and the efficiency (c) as a result of annealing at $110^{\circ} \mathrm{C}$ of MDMO-PVV:PCBM solar cells (triangles) and 'High $\mathrm{Tg}$ PPV':PCBM solar cells (circles).

Directly after preparation of the solar cells, IV-characterization was performed to obtain the initial values of the solar cell parameters. Each device was then annealed (at $110^{\circ} \mathrm{C}$, in a dark, nitrogen atmosphere) for a specific time interval (between 0 and 16 hours). After 35 hours, when all annealing treatments were finished, IV-characterization of all solar cells was redone. The final solar cell parameters were normalized with respect to the initial values. Note that the annealing temperature is above the glass transition temperature of the used MDMO-PPV $\left(\mathrm{T}_{\mathrm{g}} \approx 45^{\circ} \mathrm{C}\right)$ but below the glass transition temperature of the 'High $\mathrm{T}_{\mathrm{g}} \mathrm{PPV}$ ' $\left(\mathrm{T}_{\mathrm{g}} \approx 150^{\circ} \mathrm{C}\right)$.

The first point of the graphs in Figure 2 corresponds with the degradation of the devices due to storage at room temperature (shelf life), while the following points are obtained through annealing at $110^{\circ} \mathrm{C}$. The decay of the photovoltaic parameters due to shelf storage ageing ( 0 hours annealing time) lies in the same range for both kinds of solar cells, well above $90 \%$ of the initial values. In the further course of the graphs, there is a clear deviation for the two different materials used. The short circuit current of the 'High $\mathrm{T}_{\mathrm{g}}$ PPV' solar cells showed a small decrease due to annealing, nevertheless, its value stayed above $90 \%$ of the initial value after 16 hours of annealing at $110^{\circ} \mathrm{C}$. For MDMO-PPV based solar cells, 16 hours of annealing resulted in a decrease down to less than $60 \%$ of the initial short circuit current. The decay in fill factor for both kinds of devices roughly follows the same pattern as the decay in short circuit current. This results in the fact that the overall efficiency, being proportional to the short circuit current and the fill factor, is much more stable for 'High $\mathrm{T}_{\mathrm{g}}$ PPV' based solar cells (a decrease down to about 80\% after 16 hours of annealing) as 
compared to MDMO-PPV based solar cells (a decrease down to about 30\% after 16 hours of annealing).

Efficiencies of MDMO-PPV:PCBM based solar cells have evolved over the last decade to values up to $2.9 \%{ }^{[4]}$ In this study, the initial efficiencies for the MDMO-PPV:PCBM as well as for the 'High Tg PPV':PCBM solar cells were in the range of $1 \%-2 \%$ (without LiF and without process optimisation). In realistic outdoor conditions, the poor thermal stability of the MDMO-PPV:PCBM together with operating conditions in full sunlight (possibly up to $75^{\circ} \mathrm{C}$ ) will result in a gradual decrease of the efficiency. Though the initial values of efficiency have the same order of magnitude for both materials, we expect that, because of its better thermal stability, the 'High $\mathrm{T}_{\mathrm{g}}$ PPV':PCBM solar cells will outperform MDMO-PPV:PCBM based solar cells under full sunlight conditions in the long run.

Furthermore, a systematic Transmission Electron Microscopy (TEM) study, demonstrates that the better thermal stability of the performance for the 'High $\mathrm{T}_{g}$ PPV' solar cells coincides with a more stable morphology of the active layer. Figure 3 shows TEM images of the active layer of the MDMO-PPV based solar cells (a-e) and the 'High $\mathrm{T}_{\mathrm{g}}$ PPV' based solar cells (a'-e'). 


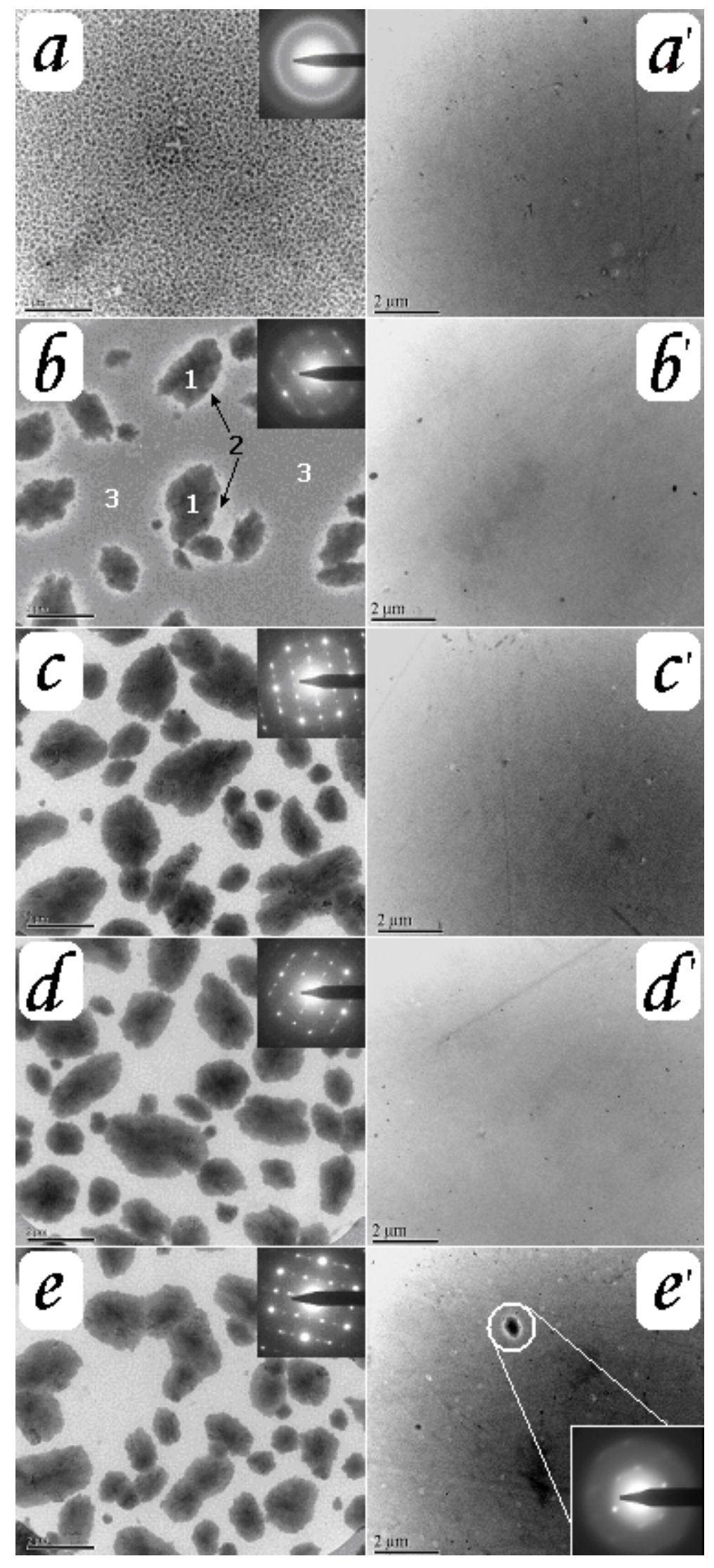


Figure 3. TEM images of the active layer of MDMO-PPV:PCBM 1:4 solar cells (a-e) and 'High $\mathrm{T}_{\mathrm{g}}$ PPV':PCBM 1:4 solar cells (a'-e'). The solar cells were annealed at $110^{\circ} \mathrm{C}$ for $0 \mathrm{~h}\left(\mathrm{a}, \mathrm{a}^{\prime}\right), 1 \mathrm{~h}\left(\mathrm{~b}, \mathrm{~b}^{\prime}\right)$, 2h (c, c'), 4h (d, d') and 16h (e, e') yielding formation of large PCBM-clusters for the MDMO-PPV based active layers while maintaining a more stable morphology for the 'High $\mathrm{T}_{\mathrm{g}}$ PPV' based active layers (scale bar: $2 \mu \mathrm{m}$ )

As mentioned already by Yang et al. ${ }^{[14]} \operatorname{large}(>1 \mu \mathrm{m})$ PCBM-clusters (dark areas, indicated as area 1 in Figure 3b) are formed upon annealing in the MDMO-PPV:PCBM active layers. The Selected Area Electron Diffraction (SAED) patterns of these clusters (insets in Figure 3) indicate that they are in fact groups of single crystals. After 1 hour of annealing at $110^{\circ} \mathrm{C}$, a light border (area 2 in Figure $3 b$ ) is visible around the PCBM-crystals. The SAED pattern of this region was compared with the SAED pattern of the area in between the crystals (area 3 in Figure 3b). Figure 4 shows the residual intensity of the SAED patterns of both regions as a function of the d-value.

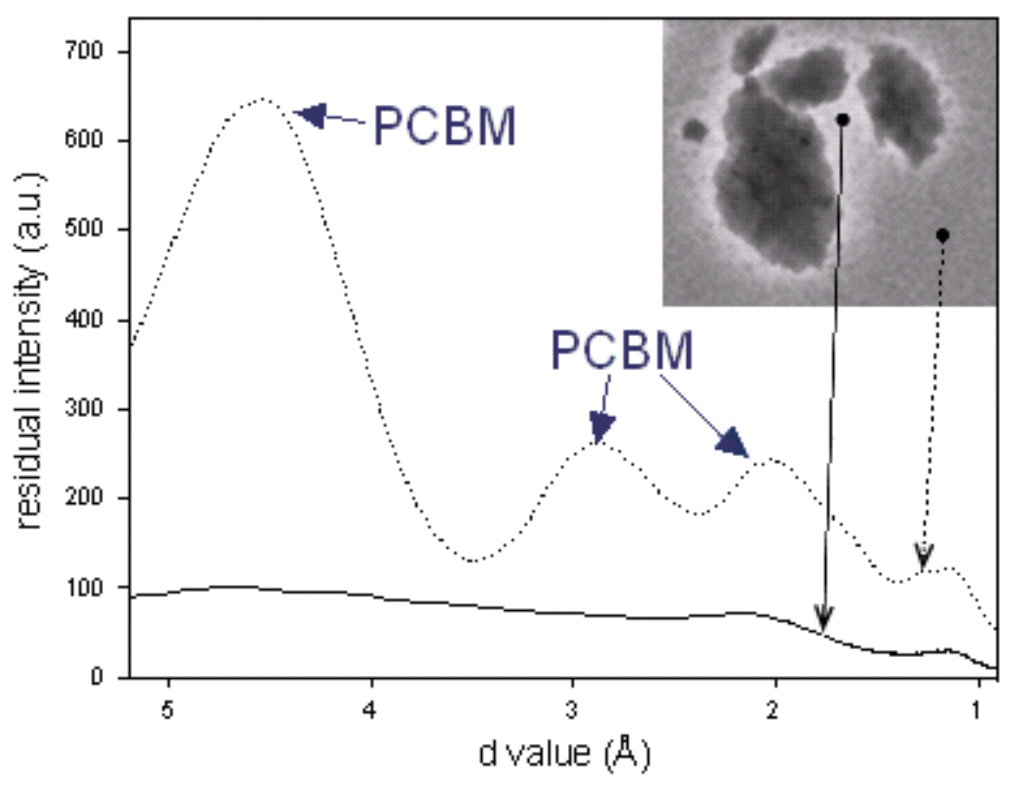

Fig. 4. Residual intensity of the SAED patterns of the light border around a PCBM-cluster (solid line) and the grey area in between the PCBM-clusters (dotted line). 
The area in between the crystals (area 3) shows intensity peaks at d-values corresponding to PCBM. ${ }^{[18]}$ In the SAED pattern of the light border around the PCBM-cluster (area 2), the PCBM peaks have disappeared. Only a broad, low intensity profile is present, which is typical for amorphous MDMO-PPV. We conclude that this light border around the PCBM-clusters is depleted of PCBM while the area in between the crystals still consists of a homogeneous MDMOPPV:PCBM blend. After 2 hours of annealing the homogeneous MDMO-PPV:PCBM matrix has vanished. All the PCBM has diffused out of the blend and is assembled in the PCBM-clusters. The TEM images of the active layer of the 'High $\mathrm{T}_{\mathrm{g}}$ PPV' solar cells (Figure 3a'-e') show a more stable morphology. It is not until after 16 hours of annealing at $110^{\circ} \mathrm{C}$ that a PCBM-cluster is found. The corresponding SAED pattern again confirms that it is a group of PCBM single crystals.

The difference in PCBM crystallization rate in MDMO-PPV:PCBM active layers and 'High $\mathrm{T}_{\mathrm{g}}$ PPV':PCBM active layers is interpreted qualitatively as a result of the difference in glass transition temperature of MDMO-PPV and 'High $\mathrm{T}_{\mathrm{g}}$ PPV'. As long as the solar cells are kept below the glass transition temperature of the polymer, the matrix is stiff and gives the PCBM molecules hardly any possibility to move freely. When a thermal treatment is applied above the glass transition temperature, it causes the matrix to become soft, making it easy for PCBM molecules to assemble. In summary, from the comparison of the thermal stability between standard MDMO-PPV solar cells and solar cells based on a material with high glass transition temperature, it can be stated that 'High $\mathrm{T}_{\mathrm{g}}$ PPV' solar cells clearly show a better thermal stability of performance and bulk morphology. This is interpreted as a more stable active layer morphology, where the free movement of the PCBM molecules is hampered due to a stiffer 'High $\mathrm{T}_{\mathrm{g}}$ PPV':PCBM matrix. The proposed approach towards thermally more stable bulk heterojunction solar cells based on the use of high $\mathrm{T}_{\mathrm{g}}$ 
polymers has therefore proven to be effective and is hence a promising route for further developments towards high efficiency, high stability organic solar cells.

\section{Acknowledgements}

The research was carried out in the framework of the IWT-project 030220 "Nanosolar", the FWOproject G025204 and the European project Molycell. Sabine Bertho is research assistant of the Fund for Scientific Research, Flanders (Belgium) (F.W.O.). Hasselt University is acknowledged for providing PhD-grants to Ilse Haeldermans. We thank Dr. H. Becker of Merck OLED Materials GmbH for the supply of the 'High $\mathrm{T}_{\mathrm{g}} \mathrm{PPV}$ '.

\section{References}

[1] G. Yu, J. Gao, J.C. Hummelen, F. Wudl, A.J. Heeger, Science 270 (1995) 1789

[2] L.S. Roman, M.R. Andersson, T. Yohanms, Adv. Mater. 9 (1997) 1164

[3] S.E. Shaheen, C.J. Brabec, N.S. Sariciftci, F. Padinger, T. Fromherz, J.C. Hummelen, Appl. Phys. Lett. 78 (2001) 841

[4] T. Munters, T. Martens, L. Goris, V. Vrindts, J. Manca, L. Lutsen, W. De Ceuninck, D. Vanderzande, L. De Schepper, J. Gelan, N.S. Sariciftci, C.J. Brabec, Thin Solid Films 403-404 (2002) 247

[5] W. Ma, C. Yang, X. Gong, K. Lee, A.J. Heeger, Adv. Funct. Mater. 15 (2005) 1617

[6] H. Neugebauer, C.J. Brabec, J.C. Hummelen, R.A.J. Janssen, N.S. Sariciftci, Synth. Met. 102 (1999) 1002

[7] F. Padinger, T. Fromherz, P. Denk, C.J. Brabec, J. Zettner, T. Hierl, N.S. Sariciftci, Synth. Met. $121(2001) 1605$ 
[8] J.M. Kroon, M.M. Wienk, W.J.H. Verhees, J.C. Hummelen, Thin Solid Films 403-404 (2002) 223

[9] F.C. Krebs, J.E. Carlé, N. Cruys-Bagger, M. Andersen, M.R. Lilliedal, M.A. Hammond, S. Hvidt, Sol. Energy Mater. Sol. Cells 86 (2005) 499

[10] S. Schuller, P. Schilinsky, J. Hauch, C.J. Brabec, Appl. Phys. A. 79 (2004) 37

[11] H. Neugebauer, C. Brabec, J.C. Hummelen, N.S. Sariciftci, Sol. Energy Mater. Sol. Cells 61 (2000) 35

[12] N. Camaioni, G. Ridolfi, G. Casalbore-Miceli, G. Possamai, L. Garlaschelli, M. Maggini, Sol. Energy Mater. Sol. Cells 76 (2003) 107

[13] X. Yang, J.K.J. van Duren, M.R. Rispens, J.C. Hummelen, R.A.J. Janssen, M.A.J. Michels, J. Loos, Adv. Mater. 16 (2004) 802

[14] X. Yang, J.K.J. van Duren, R.A.J. Janssen, M.A.J. Michels, J. Loos, Macromolecules 37 (2004) 2151

[15] H. Hoppe, N.S. Sariciftci, J. Mater.Res. 19 (2004) 1924

[16] Z. Zhu, S. Hadjikyriacou, D. Waller, R. Gaudiana, J. Macromol. Sci., Part A: Pure Appl. Chem. 41 (2004) 1467

[17] H. Becker, H. Spreitzer, W. Kreuder, E. Kluge, H. Schenk, I. Parker, Y. Cao, Adv. Mater. 42 (2000) 42

[18] M.T. Rispens, A. Meetsma, R. Rittberger, C.J. Brabec, N.S. Sariciftci, J.C. Hummelen, Chem. Commun. 17 (2003) 2116 